\title{
COMPARISON OF CFD SIMULATIONS AND MEASUREMENTS OF FLOW AFFECTED BY COANDA EFFECT
}

\section{IMPORTANCE OF THE COANDA EFFECT}

Simple example of CE is a jet blowing over convex surface. The jet could attach to the surface depending on geometrical configuration and character of the flow. Many practical applications involve near wall flows, and often in these applications of wall jets, the jet is injected at an angle to a solid boundary. Such examples can be seen in aircraft industry, energy devices (film cooling of turbine blades, gas turbine combustion chamber walls, jet exhausters, spraying devices, etc.) and many other areas. All of these devices have something in common; they were created using experimental research to assure their functionality. Design optimization is the only possible solution nowadays, as there is no proper theory to predict the CE. Finding universal description for such extensive problem cannot be expected, but there are some expectations to discover basic principles [1].

Our department is mainly focused on reduction of energy demand and improvement of functionality in devices for air conditioning and ventilation in buildings and vehicles. Particularly local ventilation in small spaces can be unpredictable because of air jet interaction with surfaces. Improvement and better control of CE for better distribution of air into the room can be made based on an analysis of wall jet physics character. Enhanced interior aerodynamics in vehicle cabs is important motivation for study of effect of different factors on the CE.

This article is focused on experimental and CFD investigation of behaviour of a jet which is travelling around surface. The main goal was describe the influence of surface geometry and properties of jet on Coanda effect formation.

\footnotetext{
- Ing. Jan Fiser, Department of Thermodynamics and Environmental Engineering, Faculty of Mechanical Engineering, Brno University of Technology, Technická 2896/2, 616 69, Brno, email: fiser@fme.vutbr.cz
}

This is an Open Access article distributed under the terms of the Creative Commons Attribution License 2.0, which permits unrestricted use, distribution, and reproduction in any medium, provided the original work is properly cited. 


\section{EXPERIMENTAL DEVICE}

An experimental test bench was designed for the CE study. The duct (5) with rectangular nozzle (4) connected to the stable board (3) was used to produce the air jet which flows around an inclined adjustable board (2), see Fig. 1 . The nozzle dimensions was: length a $=100 \mathrm{~mm}$, width $\mathrm{b}=15 \mathrm{~mm}$. These dimensions, where $\mathrm{b}<<\mathrm{a}$, were chosen as typical profile of ventilation system in vehicles. The elevation angle (measured from horizontal plane) was varied using the frame (1) from $0^{\circ}$ to $65^{\circ}$ in several steps $\left(0^{\circ}, 30^{\circ}, 45^{\circ}, 55^{\circ}\right.$, $\left.65^{\circ}\right)$. The exit velocity of the air jet was set from 2 to $15 \mathrm{~m} / \mathrm{s}$ the. The flow was considered as isothermal.
1. Frame
2. Adjustable board
3. Rigid horizontal board
4. Nozzle
5. Duct

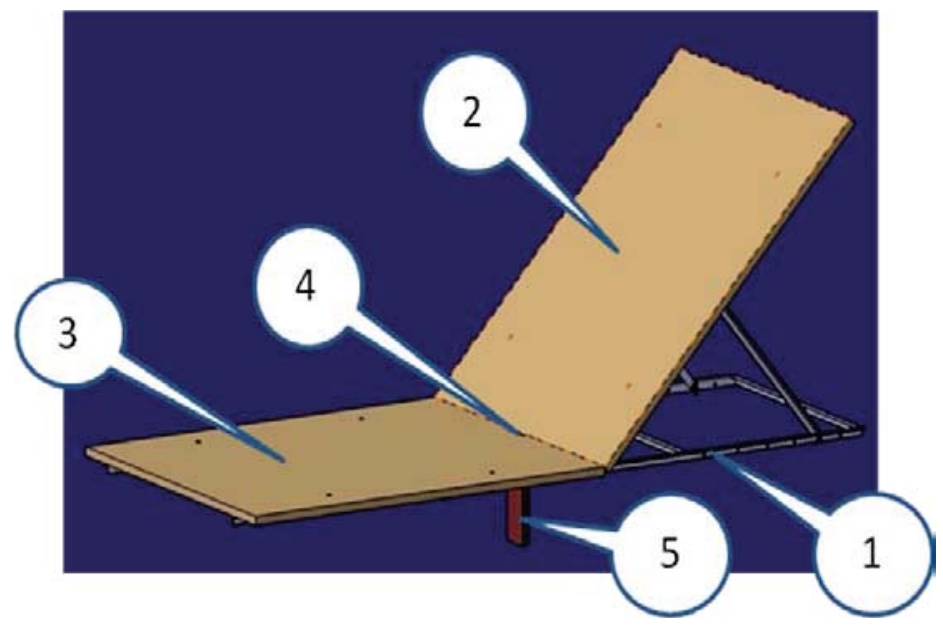

Figure 1: Experimental device

Both boards were carefully levelled using a digital level before each flow visualisation to check the inclination angle. Inflow was provided by DC ventilator placed at the front of the duct (5). Two flow straighteners were inserted into the supply duct to ensure flow with well defined velocity profile and low turbulence levels at the nozzle exit. The first one was placed behind the ventilator and the other one was close to the nozzle exit.
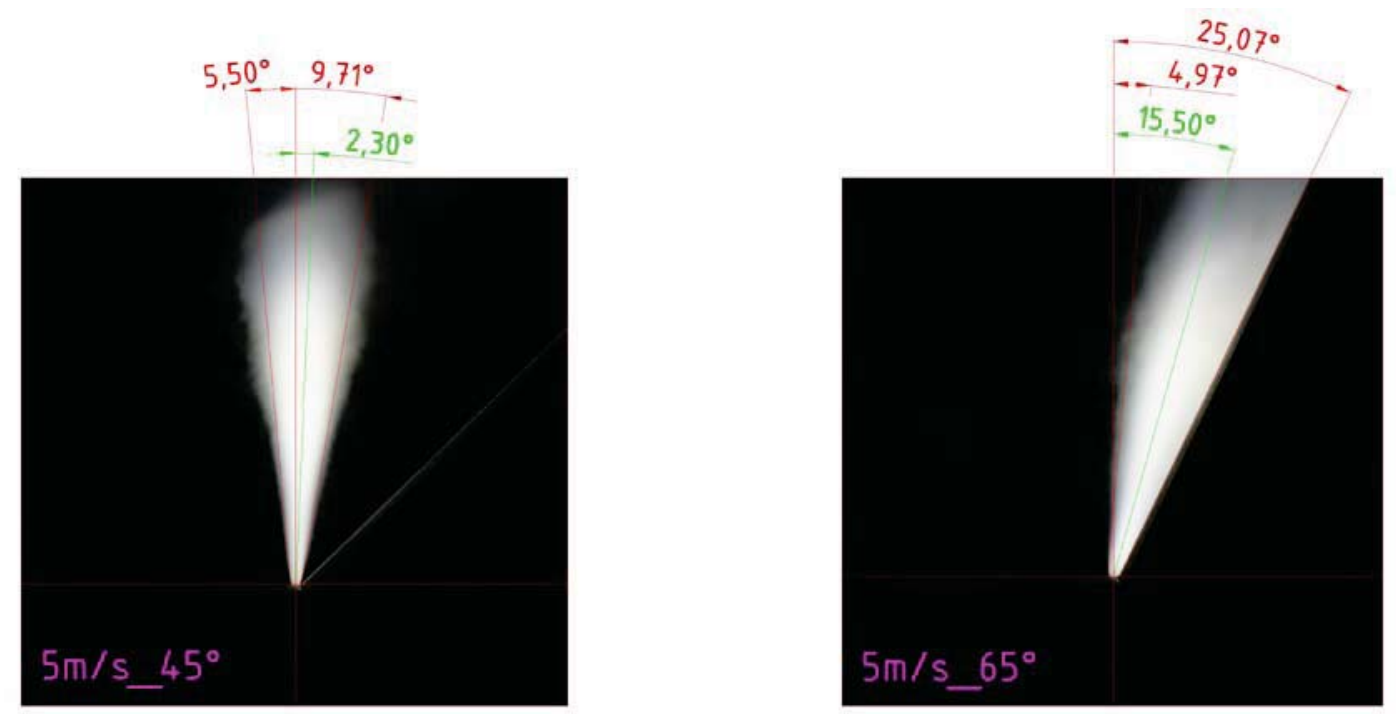

Figure 2: Example of smoke flow visualisation, exit velocity $5 \mathrm{~m} / \mathrm{s}$, angle of inclination $45^{\circ}$ (left), $65^{\circ}$ (right) 
The exit velocity was measured and controlled using CTA (Constant temperature anemometry) heated sphere probe connected to Testo 454 meter. The probe was placed horizontally at the middle of the nozzle and $1 \mathrm{~mm}$ above the nozzle. The smoke method was used for visualisation of the jet flow. The smoke was produced by smoke generator type JEM ZR22 and directly delivered into the fun suction side. The $50 \mathrm{~mm}$ wide, vertical light sheet, crossing the jet centreline was used to illuminate the jet and digital camera Canon 300 D with objective Canon EF $17-40 \mathrm{~mm}$ f/4 L USM was used for images capturing. The camera was arranged in perpendicular view to the light sheet and centred to the central point of the nozzle. Exposure time $1 \mathrm{sec}$., ISO 100 and aperture 7.1 was used throughout the experiment. About 20 photographs have been taken for each set up, and from them 10 high-quality photos were chosen for post-processing. A graphic editor was used to determine borders of the jet, based on the level of the brightness. Inclination angle of the left and right jet borders and position of the jet axis were located consequently on each of the image and averaged. The example of typical results is shown in Figure 2.

\section{CFD MODEL}

The geometry of the CFD model of was based on dimensions of the experimental stand and its location in the laboratory of ventilation. Three geometries with elevation angle of moveable board $55^{\circ}, 60^{\circ}, 65^{\circ}$ was defined. This inclinations were identify, based on results of measurements, as most promising for Coandova effect formation investigation. Model includes the air space between the boards of stand, the room ceiling and also geometry of inlet channel and nozzle geometry, see Figure 3. The distance between the ceiling and the horizontal board was more than $3 \mathrm{~m}$, thus solving of the airflow pattern was not affected by the ceiling. The space near the nozzle, near wall areas inside the inlet tubes and stand boards are the most important areas with the greatest influence on the Coandova effect prediction and therefore requires the highest quality of mesh. With this in mind, the discretization of mesh was done as shown in Figure 3: the finer division of the mesh near the nozzle, near wall area filled with prismatic cells and coarser division in peripheral areas of the network domain. Calculations were performed in the Star-CCM+ code for various boundary conditions, which were base on outlet velocities from measurements.
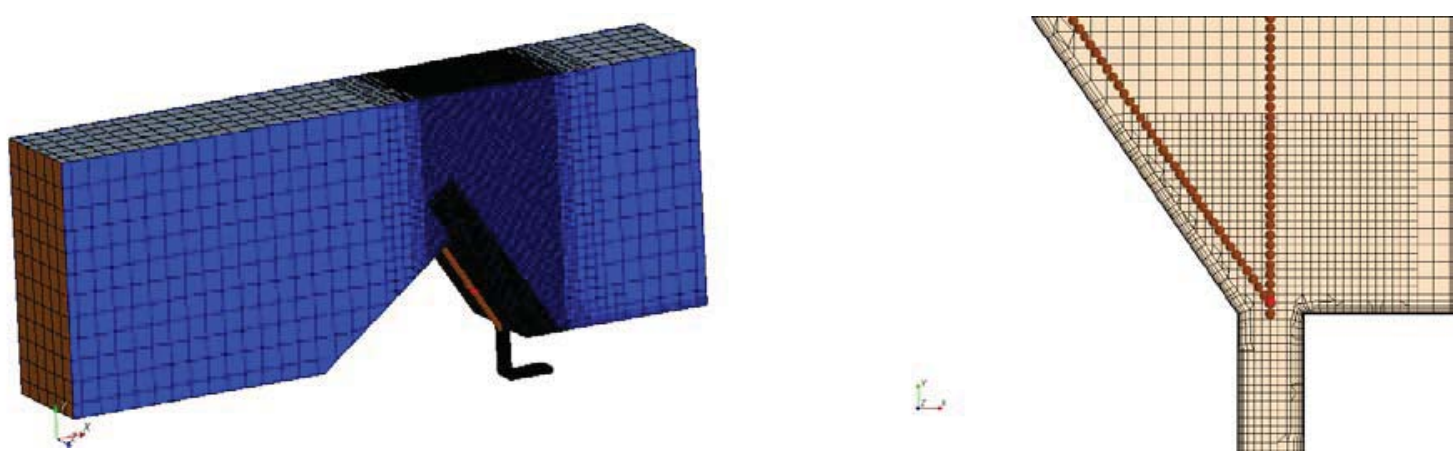

Figure 3: Geometry of mesh for elevation angle $55^{\circ}$ (left) and discretization of mesh around nozzle (right). The points define probes for post-processing. 


\section{Comparison of EXPERIMENTS Results AND CFD PREDICTION OF CoANDA EFfect}

The main aim of CFD simulation was correct prediction of jet behaviour and prediction of influence of Coanda effect. The comparison of main results is shown in Figures 4 and 5. The example of qualitative results of smoke visualisation is presented in top row of Figure 4 for moveable board inclination $45^{\circ}$ and $65^{\circ}$ and outlet velocity $5 \mathrm{~m} / \mathrm{s}$. For inclination $45^{\circ}$ the jet was not influenced by moveable board and Coanda effect was not observed. On the other hand, if inclination was $65^{\circ}$ the jet was fully attached to the moveable board due to Coanda effect. The results from CFD simulations are shown in the bottom row for same boundary conditions as experiments in laboratory. As we can see, predicted behaviour was same as behaviour of real jet and attachment of jet to the moveable board appears for inclination $65^{\circ}$.
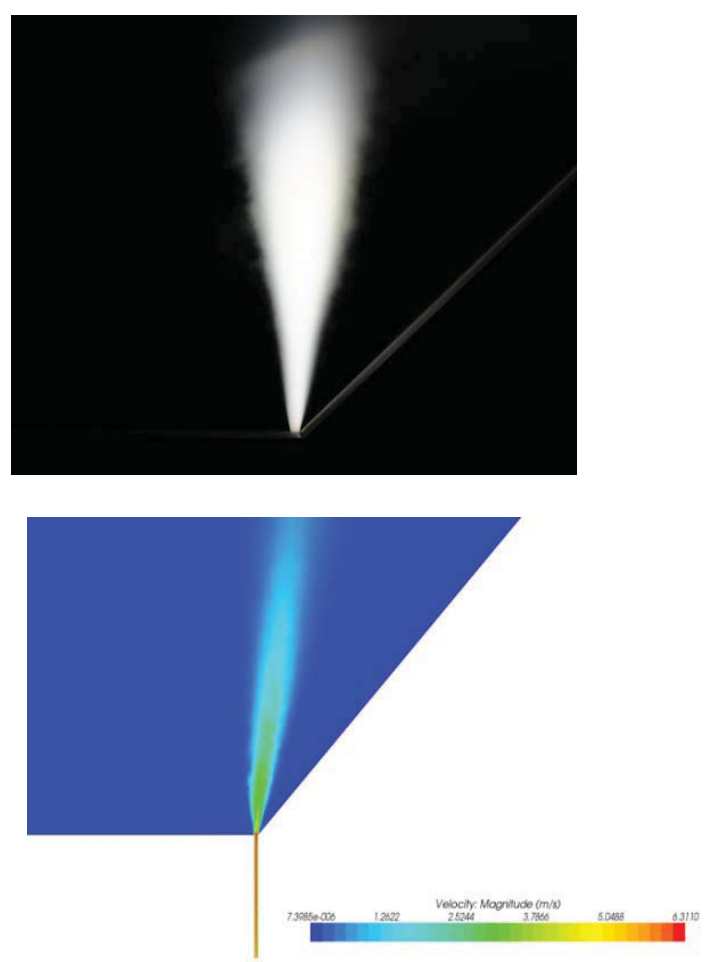
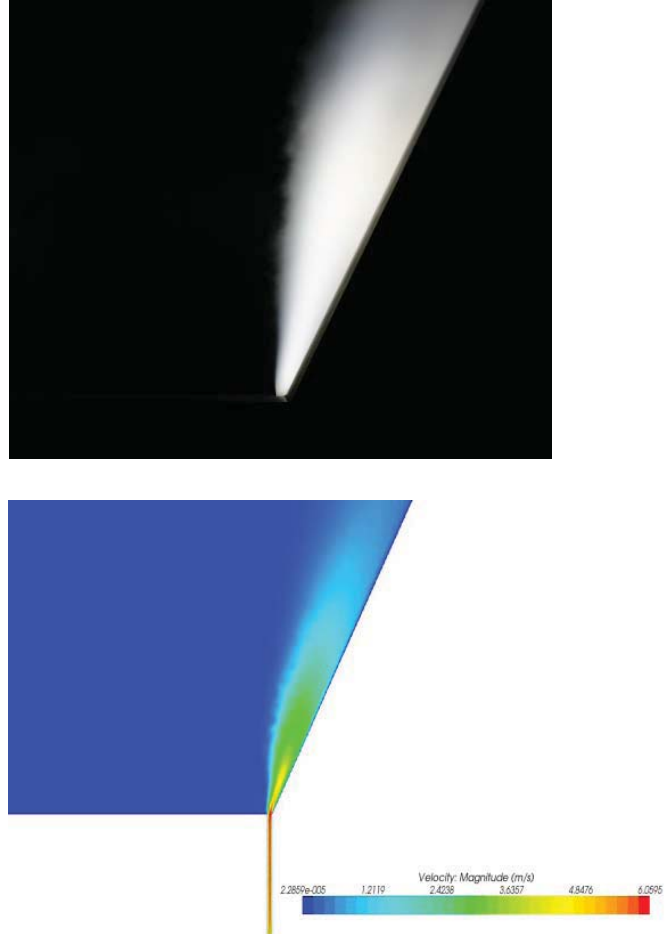

\section{Figure 4: Smoke visualisation of the flow (top row) and results of CFD simulation (bottom row), angle of inclination $45^{\circ}$ (left), $65^{\circ}$ (right)}

The results for all measured cases for experiments and simulations are shown in Figure 5. In experiments - the moveable board elevation has been varied between $30^{\circ}$ and $65^{\circ}$ and exit jet velocity from 2 to $15 \mathrm{~m} / \mathrm{s}$, in CFD - the moveable board elevation $55^{\circ}, 60^{\circ}, 65^{\circ}$ has been investigated and exit jet velocity was varied from 2 to $14 \mathrm{~m} / \mathrm{s}$. The jet inclination was significantly influenced by the angle of elevation of the moveable board and increase in the exit velocity affects turbulence intensity and causes wall jet inclination as well. This information is very important for correct prediction of CE. The jet for low elevation angles of moveable board is fully detached and it behaves like a free jet entraining fluid from the surroundings on both sides. The air entrained in the confined region between the jet and the wall is accelerated and because of 2-D character of the flow the under pressure is generated in this region. Consequently, for increased elevation 
angles the jet curves toward the wall and reattaches to the wall as shown in Figures 5 . The change from unattached to attached jet is sudden and happens for elevation angle of the moveable board higher than $55^{\circ}$. For elevation angle $60^{\circ}$ the jet is completely attached for all exit velocities expect low velocities 2 and $4 \mathrm{~m} / \mathrm{s}$ which shows unstable behaviour because of the lack of kinetic energy. For elevation angle $65^{\circ}$ the jet is completely attached for all exit velocities. The behaviour of jet observed during real experiments was same as prediction from simulations.
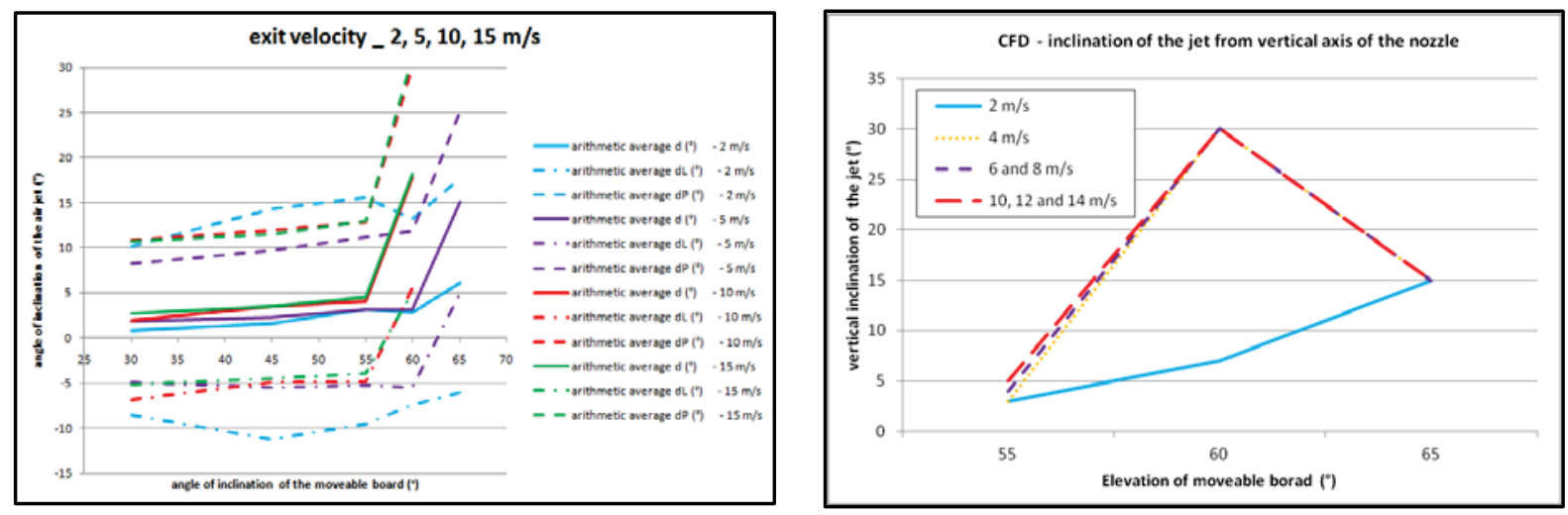

Figure 5: Angle of wall jet inclination from vertical plane - different exit velocities - measurements (left) and CFD (right)

\section{Conclusions}

The results of experimental research of the Coanda effect using the smoke flow visualization enabled to gain knowledge on important characteristics of the near wall flow. The investigation identify inclination angle $55^{\circ}$ as limit angle for Coanda effect development. Selected results of experiments were used as boundary conditions in CFD simulations. The main goal of simulations was correct prediction of behaviour of the jet affected by Coanda effect. The investigation reveals good agreement of simulations with the experiments and confirms the capability of CFD simulations for correct Coanda effect prediction.

\section{ACKNOWLEDGEMENTS}

The work was supported from Brno University of Technology project FSI-J-10-9. The work of students Bc. Petr Potočník, Bc. Lenka Bokišová and Bc. Jiří Vrbický on CFD model and post-processing of results is great acknowledged as well.

\section{REFERENCES}

[1] Lai J.C.S., Lu D.: Effect of wall inclination on the mean flow and turbulence characteristics in a two-dimensional wall jet, International Journal of Heat and Fluid Flow, Volume 17, Issue 4, August 1996, Pages 377-385. 